\title{
Retinoblastoma: An institutional experience
}

\author{
Karki $\mathrm{S}^{1}$, Upadhyaya $\mathrm{P}^{1}$, Agarwal $\mathrm{M}^{1}$, Maharjan $\mathrm{KK}^{1}$, Lavaju $\mathrm{P}^{2}$ \\ ${ }^{I}$ Department of Pathology, B.P.Koirala Instittue of Health Sciences, Dhahran. Nepal \\ ${ }^{2}$ Department of Ophthalmology, B.P.Koirala Instittue of Health Sciences, Dhahran. Nepal
}

\section{Keywords: \\ Histopathology; IRSWG; \\ Retinoblastoma; Choroid}

\begin{abstract}
Background: This article aims to describe histopathologic high risk tumor characteristics in our patient population of retinoblastoma. It is based on consensus criteria for definitions of choroidal and optic nerve invasion as outlined in The International Retinoblastoma Staging Working Group (IRSWG) 2009.

Materials and Methods: Fifty histopathologically diagnosed cases of retinoblastoma were archived from records of Pathology department during years 2004 to 2014. Re-evaluation of slides to identify choroidal and optic nerve invasion as per IRSWG along with Pathologic tumor staging was done. Data were entered into Microsoft excel sheets and results expressed in percentages. Department of Ophthalmology was consulted for recurrence of Retinoblastoma.
\end{abstract}

Results: Among fifty cases, Choroidal invasion was absent in $62 \%$ cases. Minimal invasion $(<3 \mathrm{~mm})$ was seen in $18 \%$ cases, massive $(>3 \mathrm{~mm})$ in $14 \%$ cases and extra ocular involvement in $6 \%$ cases. The optic nerve was free of tumor in more than three forth of the cases (78\%). Prelaminar and retro laminar involvement of optic nerve was observed in $6 \%$ and $10 \%$ cases respectively. Intraocular spread of tumor was observed in $6 \%$ of cases. The cut margin of optic nerve was involved in $42 \%$ while it was free of tumor in $58 \%$ of cases. Significant number of tumours were pathologically classified as pT1 (58\%) followed by pT2a (22\%). pT3a and pT4b were found in $6 \%$ each and pT3b and pT4a were found in $4 \%$ each. Recurrence was observed in two cases of PT3a and one of pT4b.

Conclusion: We conclude identifying low percentages of high risk charateristics in a retrospective histologic experience with Retinoblastoma. Recurrence observed in two tumours staged pT3a sheds light on prognostic significance of reporting massive choroidal invasion despite free cut margin. These observations call for routine practice of standardized histopathologic reporting and processing of enucleated eye samples at our tertiary care centre.

\section{INTRODUCTION}

Retinoblastoma is the most common intraocular malignant childhood tumor. ${ }^{1}$ Intracranial spread and systemic metastasis are the main causes for mortality in patients with retinoblastoma. ${ }^{2}$ Reduction in the rate of systemic tumor

\author{
Correspondence: \\ Dr. Smriti Karki, $M D$ \\ Department of Pathology \\ B.P.Koirala Instittue of Health Sciences, Dhahran. Nepal \\ dr_smritikarki@yahoo.com
}

dissemination by identification of high-risk histopathology factors after enucleation followed by appropriate adjuvant chemotherapy help improve survival. ${ }^{3}$ The current era of utilization of chemotherapy for retinoblastoma has prompted the need to standardize examination of enucleated eyes and evaluate prognostic factors. ${ }^{4}$ Currently, there is controversy about the definitions for choroidal invasion and an inconsistency in the handling of eyes with Retinoblastoma. The International Retinoblastoma Staging Working Group (IRSWG) in 2009 proposed consensus 
criteria for definitions of choroidal and optic nerve invasion agreed upon as histopathologic high risk characteristics for Retinoblastoma. ${ }^{5}$

\section{MATERIALS AND METHODS}

The study has been approved by the institutional research committee. Fifty (50) histopathologically diagnosed cases of retinoblastoma were retrospectively archived from records of Pathology department during years 2004 to 2014. Re-evaluation of slides to identify choroidal and optic nerve invasion along with Pathologic tumor staging was done as per the consensus of IRSWG. However the gross handling of enucleated specimens was not in tune with the proposed criteria owing to the retrospective nature of the study.

Pathologic staging was done as per AJCC 2010. Data were entered into Microsoft excel sheets 2007 and results expressed in percentages. Department of Ophthalmology: clinical recurrence of tumors and further correlated

\section{IRSWG PROPOSED CONSENSUS CRITERIA}

\section{DEFINITIONS:}

- CHOROIDAL INVASION: Massive choroidal invasion: a max "d" of invasive tumor focus of $3 \mathrm{~mm} />$ that may reach the scleral tissue.

Focal choroidal invasion: tumor focus $<3 \mathrm{~mm}$ and not reaching the sclera.

OPTIC NERVE INVASION:Optic nerve invasion were categorized as Prelaminar, laminar, retrolaminar, or tumor at surgical margin.

\section{RESULTS}

Maximum numbers of children 14 cases (28\%) of Retinoblastoma (fig.1) were in the age group of 36 months. It was interesting to observe the occurrence of Retinoblastoma in high frequency 42 cases (84\%) amongst children from India. The tumor was found to be present in posterior chamber only in most of the cases, 29 cases (58\%), followed by posterior chamber and uveal tract in 13 cases $(26 \%)$. Whole eyeball involvement was seen in $6(12 \%)$ cases. Both chambers and uveal tract only were involved in one case $(2 \%)$ each. Undifferentiated tumor histology was seen in more cases, 30 cases $(60 \%)$ while differentiated tumor type was seen in $20(40 \%)$ cases. In $32(68 \%)$ cases histologic high risk factor such as choroid invasion was absent but was present in 32\% of cases.(fig.2) Invasion of $<3 \mathrm{~mm}$ of choroid was $9(18 \%)$ cases while $>3 \mathrm{~mm}$ choroid invasion accounted for $7(14 \%)$ cases. Optic nerve was not involved in $39(78 \%)$ cases. Parts of optic nerve involved in descending order of frequency were $4(8 \%)$ retrolaminar (fig.3), $3(6 \%)$ prelaminar and $1(2 \%)$ laminar. In $3(6 \%)$
Table 1: Comparison of Choroidal Invasion in various reported series.

\begin{tabular}{lcl}
\hline Source, year & $\begin{array}{c}\text { Total Choroidal } \\
\text { Invasion, No./ } \\
\text { Total Eyes (\%) }\end{array}$ & $\begin{array}{l}\text { Massive Choroidal } \\
\text { Invasion, No./Total } \\
\text { Eyes (\%) }\end{array}$ \\
\hline Shields et al, 1993 & $67 / 289(23.1)$ & NA \\
\hline Khelfaoui et al,1996 & $73 / 172(42.0)$ & $20 / 172(11.6)$ \\
Biswas et al,2003 & $78 / 232(33.6)$ & $51 / 232(22.0)$ \\
\hline Gupta et al,2009 & $57 / 142(40.1)$ & $39(27.5)$ \\
\hline Orellana et al,2009 & NA & $45 / 109(41.3)$ \\
\hline Eagle et al,2009 & $49 / 297(16.5)$ & NA \\
\hline Wilson et al,2011 & $41 / 67(61.5)$ & $17 / 67(25.7)$ \\
\hline Kashyap et al,2012 & $289 / 609(47.5)$ & $150 / 609(24.6)$ \\
\hline Present study & $19 / 50(38)$ & $10 / 50(20)$
\end{tabular}

Table 2: Comparison of Optic Nerve Invasion in various reported series

\begin{tabular}{lcll}
\hline Study, year & $\begin{array}{c}\text { Retrolaminar } \\
\text { Optic Nerve, } \\
\text { No./Total Eyes } \\
(\%)\end{array}$ & $\begin{array}{c}\text { ResectedMargin, } \\
\text { No./Total Eyes (\%) }\end{array}$ \\
\hline Shields et al,1994 & $17 / 289(5.8)$ & $2 / 289(0.7)$ \\
\hline Khelfaoui et al,1996 & $33 / 172(20.0)$ & $17 / 172(10.0)$ \\
\hline Magramm et al,1989 & $66 / 841(28.0)$ & $51 / 841(21.0)$ \\
\hline Gupta et al,2009 & $24 / 142(16.9)$ & $11 / 142(7.7)$ \\
\hline Orellena et al,2009 & $22 / 109(20.2)$ & $22 / 109(20.2)$ \\
\hline Eagle et al2009 & $31 / 297(10.4)$ & $1 / 297(0.34)$ \\
\hline Wilson et al,2011 & $10 / 67(14.9)$ & NA \\
\hline Kashyap et al, 2012 & $98 / 609(16.1)$ & $45 / 609(7.4)$ \\
\hline Present study & $20154 / 50(8)$ & $3 / 50(6)$
\end{tabular}

cases, extraocular involvement was also seen (fig.4). The cut margin of optic nerve was free in $29(58 \%)$ cases while it was involved by the tumour in $21(42 \%)$ cases.

Significant numbers of tumours were pathologically classified as pT1 $29(58 \%)$ cases followed by pT2a 11 $(22 \%)$ cases. pT3a and pT4b were found in $3(6 \%)$ cases each and pT3b and pT4a were found in 2 (4\%) cases each. Recurrence was observed in two cases of PT3a and one of pT4b (6\%).

\section{DISCUSSION}

The incidence of retinoblastoma is constant worldwide at one case per 15,000-20,000 live births, which corresponds to about 9000 new cases every year. ${ }^{6}$ The disorder has no validated geographic or population hotspots. The greatest disease burden is recorded in large populations that have high birth rates, such as in Asia and Africa. ${ }^{7}$ Retinoblastoma is diagnosed relatively earlier in developed world while it is diagnosed later in developing countries, such as in Asia and Africa. ${ }^{7,8}$ This is in concordant with our study where the 


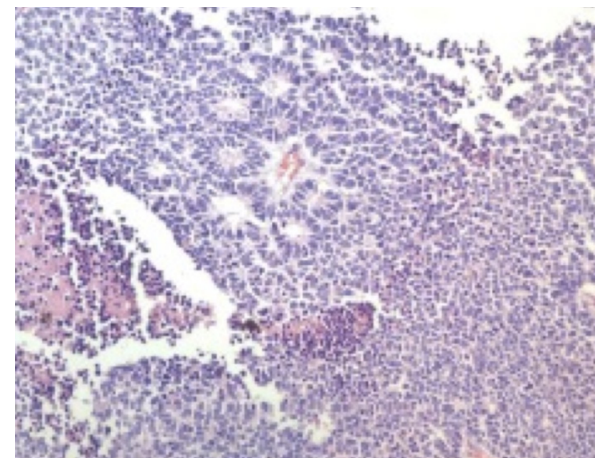

Figure 1: Photomicrograph showing formation of rosette in retinoblastoma (HE stain, X200)

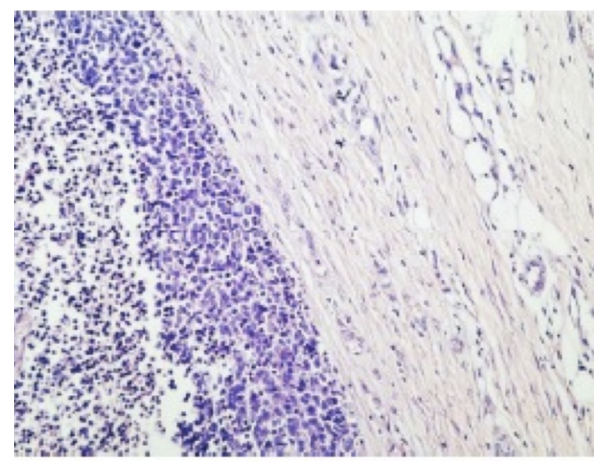

Figure 4: Invasion by tumor cells into extraocular soft tissue (HE stain, X200)

mean age at diagnosis was at a later age of 34.32 months (SD 21.2). Anterior chamber involvement by retinoblastoma is correlated with larger tumor size and is also considered as a risk factor by some authors. In our study anterior chamber was found to be involved in $14 \%$ cases which is comparable to the study done by some authors who reported it in $10 \%$ and $9 \%$ of enucleated eyes. ${ }^{9,10}$ In the current sudy, most common site of involvement by tumor is posterior chamber (58\%) followed by posterior chamber and uveal tract $(26 \%)$, posterior chamber along with anterior chamber and uveal tract $(12 \%)$ while there were single case each (2\%) of isolated uveal tract only and both chambers without concomitant involvement of uveal tract. Poorly differentiated retinoblastomas have been reported to be associated with higher recurrence. ${ }^{9}$ In our study most of the tumors were poorly differentiated $(60 \%)$ while $40 \%$ were well differentiated. Similar occurrences were reported in other series as well. ${ }^{11,12}$ On the other hand Filho et al found $95 \%$ of well-differentiated tumor in their series. ${ }^{13}$

There was a wide variation in the definition of risk criteria and in the criteria for giving adjuvant chemotherapy following enucleation. Definition of high-risk histological features and the criteria for use of adjuvant therapy is of utmost importance for the better prognosis of this potentially curable disease. ${ }^{14}$

This current era of utilization of chemoreduction and adjuvant chemotherapy for retinoblastoma mandate the

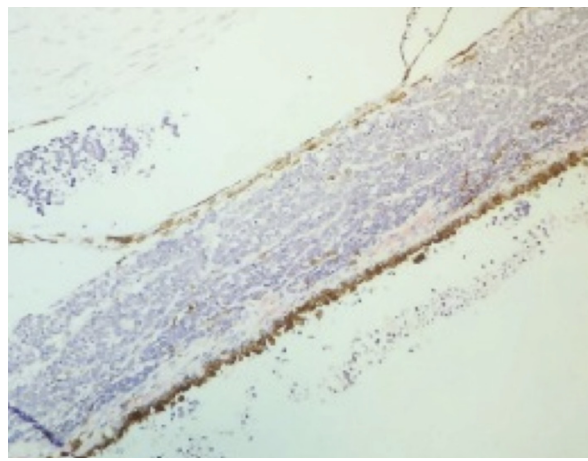

Figure 2: Choroidal invasion by tumor cells (HE stain, X200)

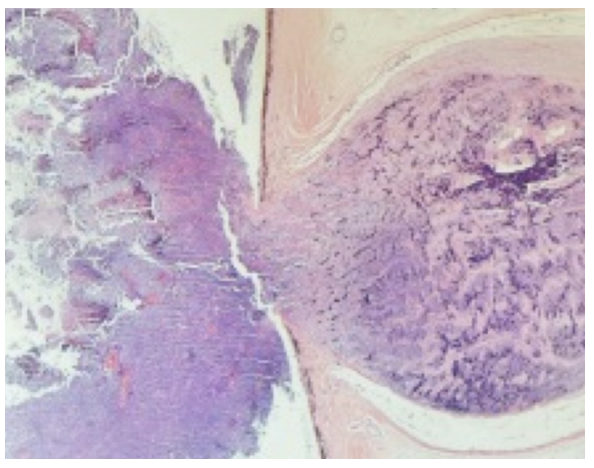

Figure 3: Post-laminar invasion of optic nerve (HE stain, X20)

need to recognize risk factors and standardize criteria across institutions and countries. To address this problem, International Retinoblastoma Staging Working Group (IRSWG) has proposed consensus criteria.

Known risk factors for systemic metastasis include involvement of the choroid, orbital tissues, retrolaminar optic nerve and involvement of the optic nerve to the line of transection. The need to identify histopathologic risk factors (HRFs) for metastasis after enucleation and to provide appropriate adjuvant therapy has been emphasized..$^{10}$ In our study the histopathological re-evaluation of retinoblastoma as per the criteria of IRSWG revealed $20 \%$ cases of massive choroidal invasion (including 6\% extraocular extension) which is comparable to that in various series, ${ }^{9,10,15}$ while Khelfaoui et al reported $11.6 \%$ and Orellana et al reported highest of all (41.3\%). ${ }^{9}$ (Table 1)

The published rates of recurrence due to optic nerve invasion shows a wide range: $7 \%$ to $56 \%$ for invasion of retrolaminar optic nerve and optic nerve to the transaction line, $12 \%$ to $42 \%$ for choroidal involvement and 3\% to $30 \%$ for scleral and extrascleral spread. ${ }^{10}$ The IRSWG consensus criteria for optic nerve invasion include classification as prelaminar, laminar, retrolaminar and surgical cut margin. ${ }^{5}$ We found that prelaminar invasion in $6 \%$, laminar invasion in $2 \%$, retrolaminar invasion in $8 \%$ and tumor at surgical cut margin in $6 \%$ cases. Retro laminar and surgical cut margin involvement by retinoblastoma has higher rate of recurrence 
and are hence risk factors. ${ }^{16}$ (Table 2).

Recurrence of malignancy is described as the reappearance of tumour cells or disease when it had apparently been eliminated. The first study examining the recurrence of retinoblastoma was done on patients enucleated between 1878 and 1929. It was published by Algernon B. Reese, and it gave a projected rate of orbital recurrence of $72 \%$. In particular, this report addressed the importance of histopathological data and the surgeon's expertise. Arif M. et al reported an orbital recurrence rate as approximately $23 \%$ and proptosis and fungating mass were considered factors that can result in orbital recurrence. ${ }^{17}$ In a large retrospective study by Kim et al.reviewing 1674 retinoblastoma patients who underwent enucleation between 1914 and 2006, seventy-one cases $(4.2 \%)$ of orbital recurrence were identified. ${ }^{17}$

This current era of utilization of chemoreduction and adjuvant chemotherapy for retinoblastoma mandate the need to recognize risk factors and standardize criteria across institutions and countries. To address this problem, International Retinoblastoma Staging Working Group (IRSWG) has proposed consensus criteria.

Histopathologic features of advanced tumor stage govern the most crucial part of disease management. In our part of world due to lack of awareness, accessibility to health care facility, resources as well as lack of policy of government, usually patients seek medical help late and hence are diagnosed in advanced stage. In the current study, significant numbers were pathologically classified as pT1 (58\%) followed by pT2a (22\%). pT3a, pT3b, pT4a and pT4b were found in $6 \%, 4 \%, 6 \%$ and $4 \%$ respectively. $20 \%$ were found to be pT3a and higher. Recurrence was observed in three cases including two cases of massive choridal invasion despite free cut margin.

\section{CONCLUSION}

The IRSWG protocol helped identify massive choroidal invasion in $14 \%$, extraocular extension in $6 \%$, and retrolaminar involvement of optic nerve in $8 \%$ cases. Recurrence observed in two tumours staged pT3a sheds light on prognostic significance of reporting massive choroidal invasion despite free cut margin. These observations call for routine practice of standardized histopathologic reporting and processing of enucleated eye samples at our tertiary care centre.

\section{ACKNOWLEDGEMENT}

This research paper is made possible through the help and support of from all co-authors, Department of Pathology and department of Ophthalmology as well as institutional research committee.

\section{REFERENCES}

1. 1. Rodriguez-Galindo C, Orbach DB, VanderVeen D. Retinoblastoma. Pediatr Clin North Am. 2015;62:201-23. Crossref

2. Sengupta S, Krishnakumar S, Sharma T, Gopal L, Khetan V. Histopathology of retinoblastoma: does standardization make a difference in reporting? Pediatr Blood Cancer. 2013 Mar;60:336-7. Crossref

3. Honavar SG. Postenucleation Adjuvant Therapy in High-Risk Retinoblastoma. Arch Ophthalmol. American Medical Association; 2002;120:923. Crossref

4. Radhakrishnan V, Kashyap S, Pushker N, et al. Outcome pathologic findings and compliance in orbital retinoblastoma International Retinoblastoma Staging System stage III treated with neoadjuvant chemotherapy a prospective study.Ophthalmology 2012;119:1470-7 Crossref

5. Sastre X, Chantada GL, Doz F, Wilson MW, de Davila MTG, Rodríguez-Galindo C, et al. Proceedings of the consensus meetings from the International Retinoblastoma Staging Working Group on the pathology guidelines for the examination of enucleated eyes and evaluation of prognostic risk factors in retinoblastoma. Arch Pathol Lab Med. 2009;133:1199-202. Crossref

6. Aerts I, Lumbroso-Le Rouic L, Gauthier-Villars M, Brisse H-J, Sastre-Garau X, Doz F. Retinoblastoma. EMC - Pediatría. 2014;49:19. Crossref

7. Dimaras H, Kimani K, Dimba E a O, et al. Retinoblastoma. The Lancet. 2012. pp1436-40.

8. Grossniklaus HE. Retinoblastoma. Fifty Years of Progress. The LXXI Edward Jackson Memorial Lecture. Am J Ophthalmol. 2014;158:875-91. Crossref

9. Kashyap S, Sethi S, Meel R, et al. A histopathologic analysis of eyes primarily enucleated for advanced intraocular retinoblastoma from a developing country. Arch Pathol Lab Med. College of American Pathologist 2012;136:190-3.

10. Gupta R, Vemuganti GK, Reddy VAP, Honavar SG. Histopathologic risk factors in retinoblastoma in India. Arch Pathol Lab Med. 2009;133:1210-4. Crossref

11. Bosaleh A, Sampor C, Solernou V, et al. Outcome of children with retinoblastoma and isolated choroidal invasion. Arch Ophthalmol. American Medical Association 2012;130:724-9. Crossref

12. Eagle RC. The pathology of ocular cancer. Eye (Lond). Nature Publishing Group; 2013;27:128-36.

13. Souza Filho JP, Correa ZMS, Odashiro AN, et al. Histopathological features and P-glycoprotein expression in retinoblastoma. Investig Ophthalmol Vis Sci. 2005;46:3478-83. Crossref

14. Chantada GL, Doz F, Orjuela M, et al. World disparities in risk definition and management of retinoblastoma: A report from the International Retinoblastoma Staging Working Group. Pediatr Blood Cancer. 2008;50:692-4. Crossref

15. Biswas J, Das D, Krishnakumar S, Shanmugam MP. Histopathologic analysis of 232 eyes with retinoblastoma conducted in an Indian tertiary-care ophthalmic center. J Pediatr Ophthalmol Strabismus. 2003;40:265-7. Crossref

16. Bouguila H, Malek I, Boujemâa C, et al. Prognosis of retinoblastoma. Report of 50 cases. J Fr Ophtalmol. 2000;24:1053-6.

17. Arif M, Islam Z. Retinoblastoma: postenucleation orbital recurrence. Can J Ophthalmol. Canadian Ophthalmological Society; 2010;45:606-9 Crossref 